\title{
José M. Alvárez de Sotomayor, un poeta olvidado (1)
}

\author{
Pedro J. Perales Larios
}

Si bien actualmente la Vida y Obra de José María Martínez Alvarez de Sotomayor, poeta y dramaturgo de Cuevas del Almanzora (Almería) -1880/ 1947 -, está siendo objeto de serios y profundos estudios, lo cierto es que han permanecido casi en el olvido desde que se produjo su muerte, a pesar de las numerosas críticas elogiosas que recibió tanto en la prensa nacional como regional, y a pesar de los clamorosos éxitos obtenidos por algunos de sus recitales y representaciones teatrales. Concretamente uno de sus dramas, La Seca, estrenada por, Enrique Borrás, en los teatros más prestigiosos de España (en El Español se estuvo representando durante catorce días consecutivos en abril de 1923) y de Argentina (Buenos Aires), según consta en los resguardos de la Sociedad de Autores que obran en mi poder, gozó de más de ciento veinte representaciones por otras companías diferentes a la de Borrás.

Del enorme éxito alcanzado por esta obra, recogido en numerosos artículos de prensa, da noticia el autor en sus Memorias con las siguientes palabras:

"Seguidamente se levanta el telón y comienza la representación de la obra. Fue verdaderamente apotésica. En el primer acto fue interrumpida la representación en cada parlamento largo para hacerme salir a escena repetidas veces y así sucedió en el segundo y así fue en el tercero, cada vez el público con más entusiasmo y emoción, siendo verdaderamente clamorosa la ovación obtenida al terminarse la obra, que también fue, en verdad, maravillosamente interpretada. Mi triunfo como dramaturgo fue definitivo. Así tuvo que reconocerlo y confesarlo la prensa de Madrid a pesar de todas las reservas y prejuicios" (2).

Los méritos literarios de sus obras le valieron la amistad y el aplauso de escritores de renombre, entre los que cabría destacar a Rubén Darío, con el que mantuvo amistosa correspondencia, a los hermanos Alvarez Quintero

(1) El presente artículo está formado en gran parte por algunas de las conclusiones, resumidas, que presenté en mi Tesis de Licenciatura, defendida en la Facultad de Letras de la Universidad de Murcia, con el título de Biografía y Obra Lírica de Alvarez de Sotomayor, el 6 de marzo de 1984.

(2) Memorias del autor. 
(3), y a Jacinto Benavente, quien en una dedicatoria autógrafa de Los intereses creados se confiesa amigo y gran admirador del poeta Sotomayor.

Las anteriores palabras pueden servir para hacernos una idea de la fama que Alvarez de Sotomayor alcanzó, sobre todo en la década de los años veinte, en los ambientes literarios de Madrid, donde solía frecuentar, además de las redacciones de numerosos periódicos, entre los que destaca El Liberal, cuyo director era su amigo, Miguel Moya, las tertulias de varios cafés. Una de ellas era la que tenía lugar en el Café El Gato Negro, punto de reunión de literatos y artistas de segunda fila, de entre los que Sotomayor gustaba destacar a su paisano y amigo, Antonio Albea, a Diego San José, a Andrés González Blanco, a Angel Fortea, al actor Albar, a Pepe Vega, a Joaquín Dicenta (hijo), a José Llovet, a José María Granada, etc.

Si ciertamente Sotomayor era bastante conocido, ¿qué sucedió para que su obra fuera paulatinamente cayendo en el olvido? Son muchas las causas y sería muy largo enumerarlas todas. Baste decir que el poeta, en las citadas Memorias, aduce como principal causa la maldad de algunos de sus paisanos que consiguieron de Borrás la renuncia a seguir representando La Seca, haciéndole creer que su autor, un rico potentado, se había servido de tan afamada compañía para incrementar su fortuna (4). Pero no fue lo más grave que Borrás dejara de representar La Seca; lo grave fue el hecho de que devolviera los originales de Pan de Sierra y Los Lobos del Lugar, de los que había comentado calidades superiores y augurado mayores éxitos.

Sotomayor estaba seguro de que la última de sus obras citadas, estrenada en el teatro, Martín de Madrid, hubiera obtenido mayor resonancia y éxito si la hubiera representado Borrás:

“..., inaugurando con su estreno una nueva etapa en el teatro madrileño Martín.

Antes de su representación, hizo la prensa una buena campaña anunciando la dignificación de este teatro arrancándolo de la chavacanería para elevarlo al teatro poético.

Sin embargo, una obra en verso estaba allí fuera de su marco porque el público que acude a este teatro es frívolo y no entiende el. verso ni le gusta lo trágico.

La obra sí tuvo éxito, que continuó durante la actuación de la empresa en Madrid y en su campaña por el Norte, pero de haberlo hecho Borrás en el Español

(3) De los hermanos Alvarez Quintero, dice Sotomayor, en sus Memorias: "Durante los entreactos era felicitado por las grandes figuras de la literatura, pero de nadie tan expresivamente como de los hermanos Alvarez Quintero, quienes me dijeron: 'Esta obra le consagra a usted de gran dramaturgo. En el tercer acto hemos olido materialmente los hmos del Almanzora"'.

(4) Memorias del autor. 
o en el Calderón quizá hubiese alcanzado aún más éxito que La Seca." (5).

Como no es el motivo de estas líneas llevar a cabo una exposición detallada de las causas que motivaron el olvido en el que hasta hace poco se ha visto sumida una obra que puede considerarse importante, sino presentar algunas de sus características para que el conocimiento de la misma se vaya generalizando, concluyo este aspecto con unas palabras de las Memorias del autor para realizar.a continuación la presentación de esas características:

"Mis libros han seguido su trayectoria sin salir de la ruta marcada por el primero, de exaltado amor a mi tierra; pero mis obras cayeron siempre sobre el surco frío del desafecto y de la indiferencia... Estoy seguro que si las mejores obras poéticas fueran mías, habrían corrido la misma suerte."

Sin ser excesivamente amplia, la producción literaria de Alvarez de Sotomayor no es de las menos voluminosas (6), y son variadas las facetas que engloba su poesía y su teatro, sobre todo la primera, dentro de la cual puede hablarse de diferentes modalidades: poesía puramente regional, con valores que a veces sobrepasan las fronteras regionales, considerados hasta ahora a un nivel de menor importancia que Gabriel y Galán, Vicente Medina y otros; poesía mística, poesía de corte academicista, romántica y modernista, etc.

Esta diversidad y la distancia cronológica que separa los años que encierran las publicaciones de sus obras (1913-1947), hace que no presente como tarea fácil un enmarque generacional de Alvarez de Sotomayor. En lo poco escrito hasta ahora sobre él y su producción son variadas las opiniones que se han apuntado con la intención de relacionarlo con un determinado movimiento literario o grupo de escritores.

Yo creo que para llegar a una amplia comprensión de su persona y obra lo que debe hacerse es, en primer lugar, especificar cuál es el verdadero valor de esta obra. En esto no hay la menor duda, todas las opiniones coinciden, la mayoría de ellas dispersas entre las páginas de los prólogos de sus obras, en considerar que la poesía de Sotomayor alcanza sus más altas cotas en lo que tiene de reflejo y documento de unas determinadas costumbres y modos de vida, con la utilización del habla propia de las gentes y la tierra que pinta.

(5) "Borrás fue enterado en Cuevas no sólo de mi gran fortuna sino que también tildaron de codiciosos los medios empleados para fomentarla y esto unido a otras falsedades aún de más mala fe, le distanciaron de mí de tal manera, que me devolvió las obras aceptadas y hasta dejó de ponerme La Seca una vez cumplidas sus obligaciones de estreno en Madrid y en América". De las Memorias del autor.

(6) Obra Editada:

Poesta: Mi Terrera, Rudezas, Alma Campesina, Campanario, Los caballeros del Campo, Isabel, Misticas y Romancero del Almanzora.

Teatro: La Seca, Los Lobos del Lugar y La Enlutaica.

Obra Inedita:

Poesia: Tratado de Melilla.

Teatro: Pan de Sierra, Honraez y Entre Parrales. 
Ello nos llevaría prescindir momentáneamente de esa otra poesía que he denominado mística y academicista, que, por otra parte, está perfectamente justificada en la trayectoria humana y literaria de su autor, pero que es una parte muy pequeña comparada con la poesía regional. Realizada ésta, podría llamarse, eliminación momentánea, quedaría efectuar, en segundo lugar, más que un enmarque generacional, un encuadramiento de la persona y la obra en la época en que vivió.

Siempre que se habla de la poesia regional de finales del siglo XIX y principios del XX se suele hacer utilizando los términos de serie de escritores más que los de grupo compacto. Al mismo tiempo se habla de escritores de segunda fila contemporáneos a los escritores del 98 y a los vanguardistas procedentes de esta Generación, que surge como un grito de protesta ante los problemas que a fectaban a España.

Valbuena Prat (7) intenta establecer una relación generacional entre Vicente Medina y el 98. En este mismo sentido Justo García Morales (8), habla de puntos divergentes entre los escritores del 98 propiamente dichos y otro 98 , en el que incluye a Vicente Medina, y también habla de conexión entre ambos 98, de una conexión más de tipo personal que literaria.

Yo creo que es en este campo en el que hay que encuadrar la obra literaria de Alvarez de Sotomayor. Por la trayectoria ideológica de los hombres del 98, por la fecha de nacimiento de Sotomayor y por los años de publicación de sus obras, esto podría parecer a primera vista anacrónico; pero si se estudia a fondo la obra de este escritor, no es difícil llegar a la conclusión, como ha hecho, Gabriel Núñez Ruiz (9), de que "ya queda lejos el modo lírico que algún escritor dieciochesco utilizó para referirse a la tierra y Sotomayor bebió de esta otra concepción impresionista y con pretensiones de atemporalidad con que los paisajistas del 98 tratarian el tema."

La visión que Sotomayor nos presenta del paisaje y el campo de su tierra, aś́ como la de sus gentes, está más próxima a la del campesino como guardián de los valores intrahistóricos unamunianos que a la del cainismo machadiano. De ahí que la sociedad presente en su obra nos la muestre el autor envuelta en unos tintes casi de ensueño fraternal entre labradores y propietarios, en la que los primeros son elevados al rango de "caballeros del campo", aunque en la realidad no sean más que abnegados y sufridos trabajadores de la tierra, de la que dependen para poder subsistir, que es lo que se desprende de una lectura rápida. Como bien apunta, Núñez Ruiz, "estos es-

(7) VALBUENA PRAT, Angel: Vicente Medina y la Generación del 98. Revista Murgetana, 20. Murcia, 1963.

(8) GARCIA MORALES, Justo: Vicente Medina y el otro 98. "Primera Semana de Estudios Murcianos", L Academia Alfonso X el Sabio, Murcia, 1961.

(9) NUÑEZ RUIZ, Gabriel. La Voz de Almeria, 17 de abril de 1982. 
critos a la tierra /.../ son la clave para entender las luchas sociales de la Almería decimonónica, porque en ellos se prolongan las polémicas surgidas durante el siglo XVIII".

Independientemente de esta conexión atemporal con el 98, probable objeto de respetables y autorizadas objeciones, la persona y obra de Sotomayor no ofrece mayores dificultades de encuadre, puesto que es obligado incluirlas dentro de lo que Valbuena Prat (10) reúne con la denominación de "una serie de fórmulas, que penetrando en el siglo $\mathrm{XX}$, son, en parte, claras derivaciones del realismo de la época anterior. Proceden del sentido anecdótico del costumbrismo y salvo contados casos de incorporación a las nuevas formas /.../ no corresponden, exactamente, en la presente centuria, a las grandes corrientes innovadoras.

Por otra parte, el teatro de Sotomayor, al estar dentro de la misma línea de su producción lírica, viene a corroborar lo anteriormente dicho. Se trata de un teatro que refleja los enfrentamientos sociales entre amos y labradores, pero que, en mi opinión, no "queda siempre interferido y desalojado - /el enfrentamiento/-, por un conflicto sentimental, estrictamente particular y no social", como opina, Ruiz Ramón (11), al hablar de la corriente de teatro social que se desarrolla entre los af́os 1915 y 1936.

Veo en Sotomayor un escritor con la suficiente emoción dramática (no sólo en su teatro, sino también en bastantes de sus poemas), para una reconsideración de su obra. No llegó, por supuesto, al extremo de algún prologuista -más que otra cosa por no haber realizado un estudio a fondo del teatro de Vicente Medina-, que vio en el teatro de Sotomayor valiosos quilates para convertirlo en un gran dramaturgo rural; como digo, no llegó al extremo de afirmar que este teatro "yace olvidado y preterido desde que $\mathrm{Vi}$ cente Medina, con mejor intención que plausible acierto, escribió El Rento. Pero es que Vicente Medina, no tenía la emoción dramática, así como tenía, $y$ en muy sabido grado de perfección, la emoción lírica..." (12). Indudablemente yo también veo en el teatro de Sotomayor esos valiosos quilates, pero sin entrar en ningún otro tipo de suposiciones ni comparaciones.

Debo advertir a quien intente una lectura seria de la obra de Alvarez de Sotomayor que nunca podría entenderla adecuadamente si pretende enfocarla desde una perspectiva exclusivamente estético-literaria, soslayando el contexto socio-económico y cultural de que es producto y la ideología casi

(10) VALBUENA PRAT, Angel: Historia de la Literatura Española, T. III. Editorial Gustavo Gili, Barcelona, 1964. 1977.

(11) RUIZ RAMON, Francisco: Historia del teatro español. Siglo XX. Eds. Cátedra, Madrid,

(12) Prólogo de Andrés González Blanco a Rudezas. En Obra Completa (poesía y teatro) de J. M. Alvarez de Sotomayor. Editorial Mary Reyes, Cuevas del Almanzora, 1973. 
anacrónica de su autor. Por ello, es imprescindible conocer datos concernientes no sólo al talante liberal de Sotomayor y a su espíritu conservador sino también a la situación económica y laboral de su pueblo natal durante los años que él vivió, dentro del marco más amplio de la Andalucía Oriental, región que no se caracteriza por el sistema latifundista que en Andaluća se viene manteniendo desde el feudalismo, sino por una distribución más equitativa de la propiedad agrícola, siendo lo normal el pequeño y mediano propietario que tiene como principal fuente de ingresos el fácil acceso a una mano de obra dócil y barata, como consecuencia de la superpoblación existènte en los primeros años del siglo $\mathrm{XX}$ :

"... viven en localidades de 10.000 a 15.000 almas, donde se va a encontrarlos para los trabajos estacionales de los cortijos. Luego, la natalidad es grande y el andaluz emigra poco. Hay, pues, superpoblación, miseria y desnutrición." (13).

Alvarez de Sotomayor conoció épocas de esplendor y crisis económicas y era consciente de que la mejor forma de poder seguir manteniendo un patrimonio, ya bastante mermado, heredado de sus antepasados, era logrando que nunca le fuera dificultoso conseguir esa mano de obra barata. Su obra, en gran medida, está enfocada a este fin. Ello lo demuestra la constancia y el dramatismo en el tratamiento de uno de los grandes problemas a que tuvo que enfrentarse su pueblo natal, a pesar de las anteriores palabras de Pierre Vilar (14), a causa de las graves sequías y crisis mineras: la emigración. Sotomayor lucha con todos los medios que tiene a su alcance para lograr que este problema le afecte a él lo menos posible. De ahí que toda su obra sea un constante lamento ante los problemas que afectan a la tierra y a las gentes que la trabajan; de ahí que se muestre su espiritu conservador intentando aferrarse a un orden en trance de desaparición, un orden de raíces decimonónicas, anorando continuamente la hermandad entre amos y campesinos. De esta forma, Alvarez de Sotomayor intentaba con su obra arrancar al campesino de su verdadera realidad social y transportarlo poéticamente a un orden casi desaparecido para que se sintiera más a gusto en su rincón, haciéndosele más difícil la decisión de abandonarlo, y se muestra al mismo tiempo como el amo que todo campesino desearía tener.

Hay que leer muy detenidamente esta obra para comprender que, desde el punto de vista ideológico, es más el producto de unos intereses particulares que del sistema, aunque al mismo tiempo sea un fiel reflejo del con-

(13) VILAR, Pierre: Historia de España. Editorial Crítica Grijaldo, Barcelona, 1978.

(14) Del mismo modo que no pueden hacerse extensivas las consideraciones sobre la propiedad agraria en Andalucía, en general, a la región que pinta Alvarez de Sotomayor en su obra, el problema de la emigración llegó a constituirse en algo verdaderamente grave en esta región:

"En Crevas, la población, desde 1910 hasta 1930, había disminuido en 12.838 habitantes; o sea, una pérdida de la mitad de la censada en la primera fecha. Cuevas regresaba a las cifras de población anteriores a 1839". (SANCHEZ PICON, Andrés: La Minería del Levante Almeriense. Editorial Cajal, Almería, 1983). 
texto político, socio-económico y cultural del que surge y encierre, además, unos valores no sólo estéticos y literarios sino también lingü ísticos.

Si desde el punto de vista ideológico la obra de Sotomayor representa el intento de mantener un orden en vías de desaparición, desde el punto de vista artístico también encierra, como acabo de apuntar, unos valores innegables que en ocasiones alcanzan altas cotas. En este sentido hay dos aspectos que merecen ser comentados: trayectoria poética y utilización lingüística.

Partiendo del romanticismo, que será constante en toda la obra, puede decirse que se distinguen dos grandes períodos separados por la guerra civil. El primero de ellos, en el que se encuentran las obras que considero más importantes -Rudezas, La Seca y Alma Campesina-, se caracteriza por la progresiva profundización en el tratamiento de los temas, que cada vez va haciendo más patente el estado de injusticia y desigualdad de los campesinos con respecto a los amos. A partir de la guerra civil esa veta lírica tan prometedora cambia de rumbo y los temas se van mostrando cada vez de forma más superficial, hasta llegar a la trivialidad en el tratamiento de muchos de ellos en su último libro, Romancero del Almanzora, tras haber pasado por un período -marcado por Isabel y Misticas - de abandono total de la poesía regional $\mathrm{y}$, por tanto, de sus ahora comprometedores temas por motivos políticos.

Por otra parte, en la poesía de Sotomayor no sólo tienen cabida el romanticismo y el realismo costumbrista, sino también el modernismo de índole neorromántica que no busca el exotismo en lo oriental sino en lo árabe, con la particularidad de que este estilo literario, además de quedar reflejado en $M i$ Terrera -primer libro publicado-, fue llevado a la práctica en su vida pública y privada, de lo cual quedó constancia en la prensa local y en un fabuloso documento por lo pintoresco y lo que de información supone para los primeros años de la carrera literaria de Alvarez de Sotomayor y un período importante de su vida (15).

Si hay una nota que pueda considerarse constante en toda esta trayectoria, ésta es el costumbrismo de valor regional que Alvarez de Sotomayor refleja con sabor decimonónico, cuyos orígenes quedan explicados así:

"El periodismo y la literatura de consumo que había comenzado a hacer pinitos en el setecientos, impulsaron el cuadro de costumbres, relacionado con los bocetos fisonómicos y la frenología. El lector actual ha de buscar en ellos algo más que una página desvaída de la historia literaria; el costumbrismo ofrece un espléndido retablo de España con su galería de tipos populares que pululan en la urbe y los campos; cada región encuentra su daguerrotipo." (16).

(15) El documento en cuestión -que no fue editado - se titula Documentos para la Historia del Califato. Visirato de Instrucción Pública, y está formado en su mayor parte con recortes de prensa que fueron apareciendo en El Imparcial de Levante, semanario que estuvo editándose en Cuevas entre los años 1913 y 1915.

(16) BLANCO AGUNAGA, Carlos; RODRIGUEZ PUERTOLAS, Julio; IRIS ZAVALA, M.: Historia Social de la Literatura Española. Editorial Castalia, Madrid, 1978. 
Este modo de hacer literatura aún presente en el siglo $\mathrm{XX}$, es considerado por un grupo de escritores como el terreno más abonado para velar por unos intereses determinados. Entre ellos hay que incluir, impulsado por motivaciones de interés exclusivamente personal, a Alvarez de Sotomayor, a quien cuadran de forma muy apropiada las siguientes palabras:

El costumbrismo recoge tradiciones, usos, actitudes ya desaparecidas, pero que sirven para comprender a esa Espana decimonónica donde coinciden en un mismo punto el pasado anquilosado y el presente de esperanzas. Algunos escritores elogiaban la España pintoresca - romantique Espagne'-, no contaminada por el espíritu burgués, el capitalismo y la industrialización. En el fondo exaltan los privilegios señoriales del Antiguo Régimen: el pueblo campesino y el que emigraba a la urbe en busca de trabajo es para el costumbrismo conservador y estático o de consolación el depositario de la Espanfa eterna, cristiana y monárquica. Pero solo veían la apariencia 0 , mejor dicho, le imponían esos valores a un pueblo levantisco, al que temian." (17).

También en el aspecto métrico se aprecia una paulatina trayectoria de predilección progresiva hacia el romance y las formas populares. La utilización del romance oscila entre la ausencia total en Mi Terrera, hasta llegar a ser el único esquema utilizado en Romancero del Almanzora, respectivamente primero y último de los libros de Sotomayor.

Pero donde la trayectoria poética alcanza mayor relevancia y grado de preocupación constante y consciente es en la depuración llevada a cabo en la plasmación del habla del Campesino de Cuevas. En este campo la obra comentada es un valiosísimo documento $y$ fuente de información para el estudio del habla de esta ciudad en la época que el autor retrata. Desde la incipiente intención de transcribir algunos rasgos de esta modalidad de habla en Mi Terrera. Sotomayor pasa por todos los grados de plasmación de la realidad de una lengua destinada a morir con sus hablantes. Así, en Rudezas hace un prodigioso alarde de maestría en el reflejo de todas las características fonéticas, léxicas y morfosintácticas, manifestadas en sus más ruda y fiel espontaneidad, del habla del campesino de Cuevas. En el siguiente libro, Alma Campesina, la técnica seguida es la misma, pero ahora la labor de depuración se hace patente en la plasmación de los mismos niveles lingü ísticos con características mucho más dulcificadas que en el libro anterior. Al leer su último libro, Romancero del Almanzora, y comprobar que la lengua utilizada ahora no presenta el mismo grado de elaboración, sino que ésta disminuye, cabría preguntarse si la guerra civil no fue también el mativo de que Alvarez de Sotomayor, al no poder trabajar los temas con la profundidad que él hubiera deseado, considerara que la mejor manera de equilibrar fondo y forma

(17) Idem. 
era dejando constancia de su despreocupación por el habla, habida cuenta del grado de depuración alcanzado en los libros anteriores.

Por todo lo dicho, concluyo estas líneas repitiendo que la persona y obra de José M. Alvarez de Sotomayor ha sido, desde su muerte, injusta y paradójicamente por ser el poeta que más ha cantado su tierra y las gentes que la habitan, un gran desconocido incluso entre esas mismas gentes, y considero que encierran valores suficientes para ser objeto de estudios a fondo $y$, además, para ser de nuevo reconsideradas, si es que alguna vez lo fueron. 